\title{
EXPERIMENTAL INVESTIGATION OF THE BOND BETWEEN GLASS TEXTILE REINFORCED MORTAR (GTRM) AND MASONRY SUBSTRATE: THE EFFECT OF TEXTILE IMPREGNATION
}

\author{
PARASKEVI D. ASKOUNI ${ }^{*}$ AND CATHERINE G. PAPANICOLAOU ${ }^{2}$ \\ ${ }^{1}$ Structural Materials Laboratory (SML) \\ University of Patras (UP) \\ Rio Patras, 26504, Achaia, Greece \\ e-mail: askounip@upatras.gr, http://sml.civil.upatras.gr/ (*corresponding author) \\ ${ }^{2}$ Structural Materials Laboratory (SML) \\ University of Patras (UP) \\ Rio Patras, 26504, Achaia, Greece \\ e-mail: kpapanic@upatras.gr, http://sml.civil.upatras.gr/
}

Keywords: Textile Reinforced Mortar, Masonry, Bond, Impregnation

\begin{abstract}
Textile Reinforced Mortar (TRM) is an appealing choice for the strengthening of existing structures and especially that of monumental character through application as external reinforcement. In the current study, the TRM-to-masonry bond was experimentally investigated focusing on the parameter of the yarns' treatment, that is none or impregnation with Styrene-Butadiene Rubber - SBR latex. For this purpose, both double-lap/double-prism (DL) and single-lap/single-prism (SL) shear bond test configurations have been employed. Specimens comprised strips of glass fiber textiles (either uncoated - UT or fully impregnated - IT) applied on wall prisms of stack-bonded smooth clay units through a cement-based mortar. TRM strips of DL specimens (with uncoated textile - UT or impregnated textile - IT) had a bond length (BL) equal to $150 \mathrm{~mm}$. This BL was larger than the effective one, i.e. the minimum length needed for the attainment of the maximum TRM bond capacity (with UT). Due to the inadequacy of the DL set-up in capturing specimens' post-peak response, the SL set-up was also opted for. TRM strips of SL specimens (with UT or IT) had various BLs (100 $\mathrm{mm}, 150 \mathrm{~mm}$ and $200 \mathrm{~mm}$ ) in order to study the combined effect of BL and textile impregnation. According to the results from both set-ups, the maximum bond load, $F_{\max }$ of specimens with IT was increased by $40 \%$ in comparison with specimens with UT. Additionally, $F_{\max }$ of specimens with IT increased with increasing $B L$.
\end{abstract}

\section{INTRODUCTION}

Textile Reinforced Mortar (TRM) is a composite material comprising fiber grids embedded in an inorganic (typically, cement- or lime-based) matrix. The textiles used consist of dry or coated (partially impregnated) or fully impregnated fiber yarns (although, it is debatable whether such a treatment leads to composites that should be put under the TRM umbrella). TRM systems have been gaining the technical world's acceptance as externally 
bonded strengthening means of existing masonry structures (see [1] for a compilation of successful interventions in real-life structures). Especially, in the case of structures of a monumental character, TRMs' compatibility with various substrates, (partial) reversibility of the intervention and substrate breathability render this composite material as an appealing choice for strengthening. However, the efficient use of TRMs significantly depends on both the bond between the composite material and the existing substrate and the bond between the grid and the matrix. Unless certain unfavourable conditions are met, it has been shown that the most vulnerable interface during in-plane shear load transfer from the substrate to the textile is the textile-to-matrix interface in respect to the TRM-to-substrate one $[2,3]$. The current study focuses on the effect of the yarns' treatment (impregnation with polymers or lack thereof) on the improvement of textile-to-matrix bond. This type of yarns' treatment can eliminate the well-documented telescopic pull-out phenomenon i.e. the relative slippage of unbonded ('dry') inner filaments in respect to the mortar-bonded sleeve ones during yarns' pull out from the matrix. It is noted that in dry fiber yarns this distinction between inner (or core) filaments and outer (or sleeve) ones is due to partial penetration of the matrix into the yarns; the degree of penetration depends on a multitude of parameters such as the consistency of the matrix, the weight of the yarn and the production method of the TRM.

A previous relevant study is that of [4] who concluded that the bond capacity of a TRM system consisting of a carbon fiber textile embedded in a pozzolanic mortar applied onto clay bricks was improved through a treatment involving yarns' (moderate or complete) impregnation with a flexible epoxy resin combined with quartz sanding. Furthermore, by application of a carbon fiber textile on Masonry substrates by means of a lime-based mortar
[5] studied the simultaneous effect of TRM bond length and yarns' treatment (complete
impregnation with a flexible epoxy resin in combination with quartz sanding). According to
the experimental results of the latter study, the matrix-to-textile bond improvement due to
textile treatment was more pronounced for increasing bond lengths. In the work of [6], a Round Robin test campaign was undertaken in order to assess the TRM-to-masonry bond

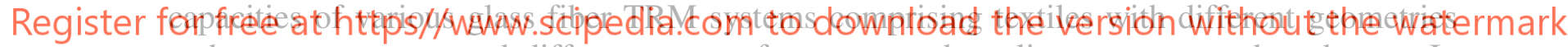
and yarn treatments and different types of mortars such as lime- or cement-based ones. In particular, the comparison of the maximum axial textile stress of some GTRM systems combining coated or uncoated textiles with lime-based mortars and pre-impregnated textiles with lime- or cement- based mortars ended up to similar stress values concerning the coated and uncoated textiles (however more scattered in the case of dry fibers) and higher stress values concerning the pre-impregnates ones.

Yarn's impregnation (partial or complete) results in: (i) improved matrix-to-yarn bond; (ii) improved stress distribution among both different filaments within the same yarn and different yarns within the same textile layer; and hence (iii) better exploitation of the fibers' tensile capacity [see also 7]. In TRM/masonry joints and in the absence of debonding phenomena along the TRM/masonry interface, this translates into an increase in the loadbearing capacity of the joints under in-plane shear loads. Nevertheless, strength improvements are not always the critical ones, especially when structural upgrading interventions of unreinforced masonry structures against seismic actions are called for. In these cases, energy dissipation of the strengthened structure is a crucial feature. Under this light, dry or coated fiber yarns failing under telescopic pull-out can provide the strengthening system with favourable energy dissipation characteristics. Moreover, yarns' impregnation (or even 
coating) with polymers entails some drawbacks, such as: (i) 'stiffening' of the textile resulting in its inability (partial or complete, depending on the impregnation degree achieved and on the type of impregnating means applied, e.g. thermoset polymer or synthetic rubbers) to closely match irregular surfaces; and (ii) thermal decomposition of the polymeric coating/impregnation means at exposure temperatures larger than (roughly) $400^{\circ} \mathrm{C}$, leading to matrix-to-textile bond deterioration as shown from pull-out tests run on post-heated/cooleddown textile reinforced concrete specimens [8]. Nevertheless, it should be mentioned that polymers are not the only option as materials for yarns' coating/impregnation; for example, cement slurries or other minerals can be used for this purpose, see $[9,10]$.

The experimental results presented herein are the products of a campaign focusing on the effect of textile complete impregnation with a Styrene-Butadiene Rubber (SBR) latex emulsion on the bond capacity of AR glass TRM overlays bonded on masonry substrates. The study involved shear bond tests of both the double-lap/double-prism (DL) and the singlelap/single-prism (SL) type. In this work, SBR was used on the basis of its ability to ensure partial pull-out of the core filaments [11] (and, hence, to yield higher energy dissipation composite features) in comparison to epoxy-resins [12] (comparisons made with carbon fiber yarns, though).

\section{MATERIALS}
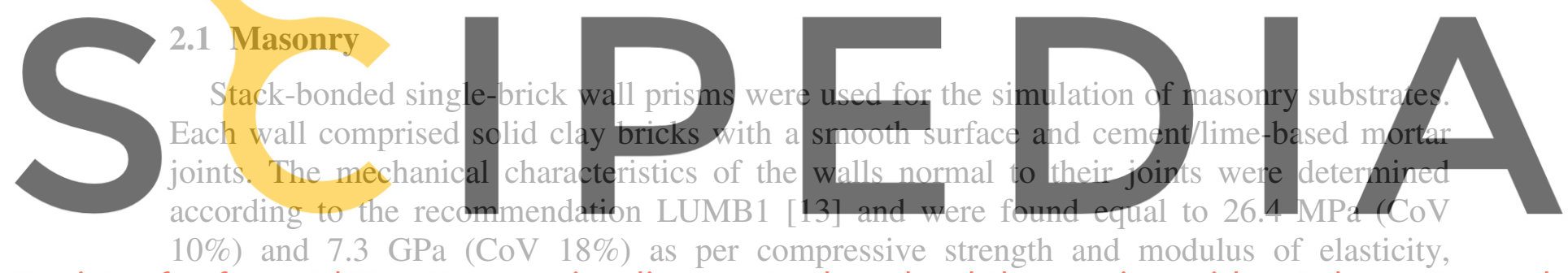
$10 \%)$ and $7.3 \mathrm{GPa}(\mathrm{CoV}$ 18\%) as per compressive strength and modulus of elasticity,

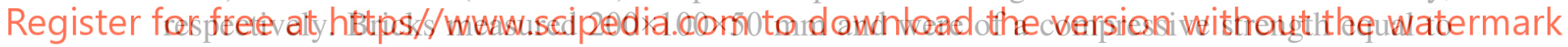
$20 \mathrm{MPa}$, according to the producer. Joints were approximately $15 \mathrm{~mm}$ thick. For their construction a M5 general purpose masonry mortar, according to the Eurocode 6 [14] classification, was used containing cement (CEM IV 32.5N), lime and sand in proportions $1: 2: 6$, by volume.

\subsection{TRM}

Two TRM systems were investigated sharing the same cement-based mortar (matrix) and the same AR-glass fiber textile the only difference being in the yarns' treatment: (i) dry, i.e. "as produced", henceforth referred to as UT (uncoated textile) versus (ii) fully impregnated by hand using a Styrene-Butadiene Rubber - SBR latex emulsion, henceforth referred to as IT (impregnated textile). The dry textile (with a balanced arrangement of yarns in two orthogonal directions) had an areal weight and a mid-yarn spacing equal to $320 \mathrm{~g} / \mathrm{m}^{2}$ and $12 \mathrm{~mm}$, respectively. Both textiles were mechanically characterized through tensile tests on 9-yarns' strips; testing was carried out partially according to EN ISO 13934-1 [15]. According to the results, the tensile strength $\left(f_{t}\right)$ and the elastic modulus of UT were equal to $822 \mathrm{MPa}(\mathrm{CoV}$ $7 \%)$ and $71 \mathrm{GPa}(\mathrm{CoV} 6 \%)$, respectively. The respective values for IT were found equal to 
$1126 \mathrm{MPa}(\mathrm{CoV} 1 \%)$ and $66 \mathrm{GPa}(\mathrm{CoV} 1 \%)$, respectively. The mortar used as matrix contained polypropylene fibers and a low content $(<5 \%$, by weight of cement) of polymeric additives for the avoidance of shrinkage phenomena. The compressive and flexural strengths of the mortar were determined according to EN 1015-11 [16] at 21 days post-production and were found equal to $22.3 \mathrm{MPa}(\mathrm{CoV} 11 \%)$ and $5.2 \mathrm{MPa}(\mathrm{CoV} 14 \%)$, respectively; its elastic modulus was equal to $7.6 \mathrm{GPa}$ (as provided by the manufacturer).

\section{EXPERIMENTAL PROGRAM}

\subsection{Set-ups employed}

Both double-lap/double-prism (DL) and single-lap/single-prism (SL) set-ups were employed for reasons explained in the following (see subsection 4.2). Specimens involved in DL tests consisted of two wall prisms connected with a single TRM overlay on each side, (Figure 1). Each TRM overlay was made of two mortar layers of equal thickness (around 3 $\mathrm{mm}$ ) and a single uncoated or impregnated textile strip sandwiched between them. The total length of the TRM overlay was equal to double the examined bonded length plus the unbonded length, which was equal to $100 \mathrm{~mm}$ (50 $\mathrm{mm}$ space between the wall prisms plus $2 \times 25 \mathrm{~mm}$ starter unbonded lengths introduced for the avoidance of stress concentration phenomena). The TRM overlay was centrally bonded on the walls widthwise and its width was $120 \mathrm{~mm}$ comprising 9 longitudinal (load-aligned) yarns. Specimens were moist-cured using wet burlaps for 7 days and then stored in lab conditions for 14 more days until testing. Each wall prism was fitt (fixed) and the top (no through centrally-positioned ensure self-alignment of the realized by imposed
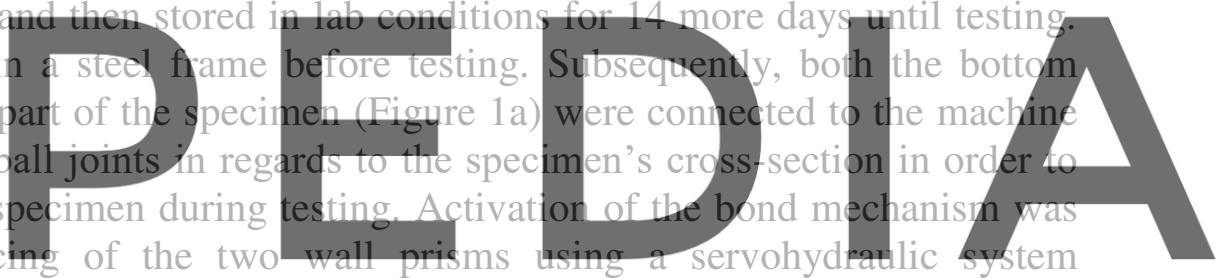

furnished with a $50 \mathrm{kN}$ load cell. Tests were run in a displacement-control mode at a constant

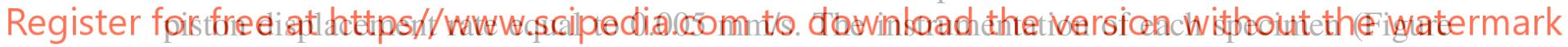
1a) consisted of: (i) two digital dial gauges (DDG) placed adjacent to the strip's loaded ends (DDGLE) on each side of the specimen in order to measure the distancing between the two wallettes; (ii) two DDG placed at the strip's free ends (attached on the central textile yarn DDGFE) on a single side of the specimen (henceforth side A), in order to record the slip of the projecting textile at this position; (iii) three strain gauges along each TRM half-overlay and one at the overlay's unbonded length (side A), mounted on the central yarn of the textile, through slots; (iv) a random pattern of black dots on the opposite side of side A which was previously painted white (henceforth side B) in order to conduct post-test DIC analysis.

Specimens involved in SL tests comprised a single wall prism unilaterally reinforced with a TRM overlay constructed as described for the case of DL specimens. The TRM strip was centrally bonded on the wall widthwise distancing $25 \mathrm{~mm}$ from the wall's top edge so that stress concentration phenomena could be avoided. The total length of the TRM overlay was equal to the examined bond length while its width was equal to $120 \mathrm{~mm}$ (9 yarns). The textile projected from both the top and the bottom parts of the TRM strip (Figure 1b). Curing conditions of the specimens were the same to those of DL ones. Each wall prism was placed and fixed in a steel frame connected to the moving part of the machine. The projecting textile at the top was connected to the fixed part of the machine through a joint providing full in- 
plane and partial out-of-plane rotation capacity. The top end of the textile strip was sandwiched between two fiber-reinforced polymer tabs and fixed between two bolted steel plates. During testing, the projecting textile was being pulled away from the bonded TRM overlay using a servohydraulic testing machine fitted with a $250 \mathrm{kN}$ load-cell; piston displacement was the controlling command at the same rate as that in DL tests. The instrumentation of each specimen (Figure 1b) consisted of: (i) two DDG fixed on the wall acting against an aluminium plate which was glued on the first transversal yarn of the pulled textile close to the strip's loaded end in order to measure the relative displacement of the textile in respect to the wall; (ii) two DDG fixed on the wall acting against an aluminium plate which was glued on the second transversal yarn of the textile close to the strip's free end, in order to record the slip of the textile at this position; (iii) three strain gauges along the TRM overlay mounted on the central yarn of the textile, through slots.
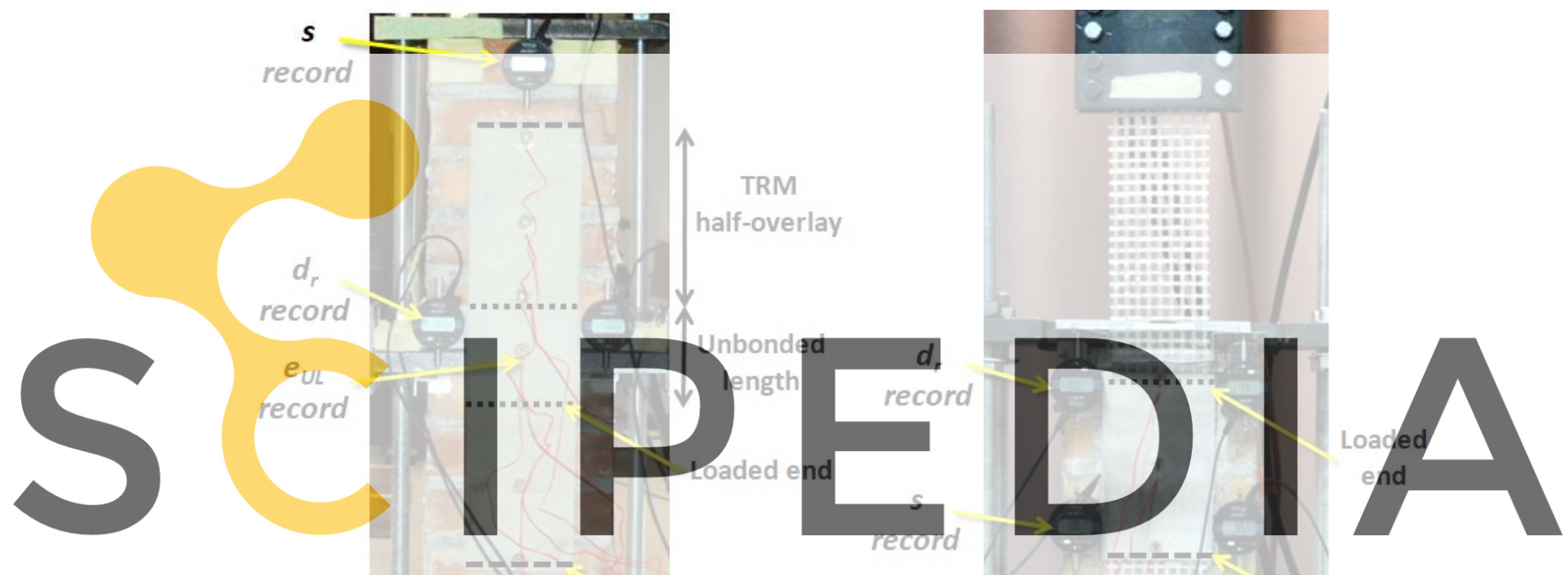

(a) Free end
Free to download the version without th (b)

Figure 1: (a) Double-lap/double-prism and (b) Single-lap/single-prism set-up

\subsection{Specimens}

In total, 5 DL and 12 SL specimens are presented in the current study. In the case of DL specimens, the bond length of the TRM overlays was equal to $150 \mathrm{~mm}$ while 3 of them were furnished with UT and the rest with IT. The selected bond length was higher than the one previously determined as the effective bond length of identical TRM/masonry joints with UT (assessed by DL shear bond tests) [3]; the latter was found equal to $125 \mathrm{~mm}$. In the case of SL specimens, half of them were furnished with UT and the remaining with IT while also varying the examined bond lengths $(100 \mathrm{~mm}, 150 \mathrm{~mm}$ and $200 \mathrm{~mm})$. Specimens' notation has the form of BLx_y_z_n (see Table 1), where $\mathrm{x}$ is the bond length (BL) of the TRM overlay in $\mathrm{mm}$, $\mathrm{y}$ is the type of set-up employed (DL or SL), $\mathrm{z}$ is the type of textile employed (UT or IT) and $\mathrm{n}$ is the specimen number in a group of identical specimens. 


\section{EXPERIMENTAL RESULTS}

\subsection{Response curves and values}

The experimental results are listed in Table 1. For the DL specimens, each tabulated value was derived as follows: (i) maximum load of each TRM half-overlay, $F_{\max }$, being equal to half of the piston load at maximum (assuming equal piston load distribution between the two reinforced sides of the specimen due to its symmetry [3]); (ii) maximum textile axial stress, $\sigma_{\max }$, being equal to the ratio of $F_{\max }$ to longitudinal fibers' area $A_{f}\left(=6.912 \mathrm{~mm}^{2}\right.$ ); (iii) relative displacement of each TRM half-overlay in respect to the wall prism at maximum load, $d_{r, \max }$, being equal to one half of the average of the four readings from the DDGLE minus one half of the elongation of the unbonded length per side (taken equal to the strain gauge reading times the unbonded length); (iv) the elongation corresponding to maximum load, $e_{B L}$, being equal to the mean value of the strain integrals of the TRM half-overlays on Side A; (v) the slippage corresponding to maximum load, $s_{B L}$, being equal to the difference between the $d_{r, \text { max }}$ and $e_{B L}$ values (see also [3]); (vi) textile exploitation degree being equal to the ratio of $\sigma_{\max }$ to $f_{t}$. It is noted that both the relative displacement and the slip of the two TRM half-overlays of the same side were assumed to be equal (see also [17]). For the SL specimens, the derivation of the values included in Table 1 was realized as in the case for DL specimens with the following exceptions: (i) maximum load, $F_{\max }$, was equal to the piston maximum load (ii) relative displacement at maximum load, $d_{r, \max }$, was equal to the average of the readings from TRM overlay. The failu All DL and SL spec

from within the matrix. In the case of DL specimens failure bearing capacity) was associated to the enlargert along the unbonded length (Figtire 2a) which
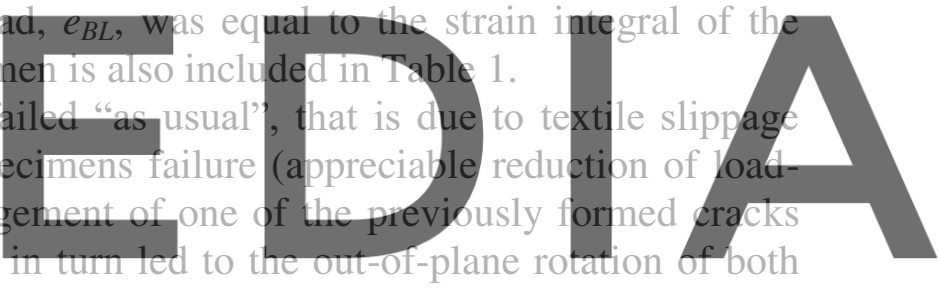
wall prisms and the loss of specimens' symmetry (Figure 2b). SL specimens with IT failed

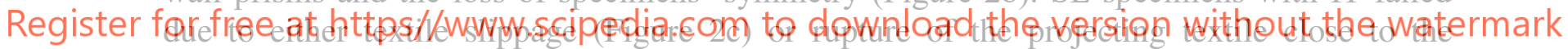
gripping device (bolted steel plates) due to stress concentration [Figure $2 \mathrm{~d}$ and $\left(\sigma_{\max } / f_{t}\right)$ values in Table 1, all less than 1). It is clanified that in neither DL nor SL specimens were cracks formed along the bonded part of the overlay or did any interlaminar shear failure or TRM-to-substrate debonding phenomena occur. 
Table 1: Experimental results

\begin{tabular}{|c|c|c|c|c|c|c|c|}
\hline Specimen & $\begin{array}{l}\boldsymbol{F}_{\max } \\
(\mathrm{kN}) \\
\end{array}$ & $\begin{array}{c}\sigma_{\max } \\
(\mathrm{MPa})\end{array}$ & $\begin{array}{l}\boldsymbol{d}_{r, \max } \\
(\mathrm{mm})\end{array}$ & $\begin{array}{c}\boldsymbol{e}_{\boldsymbol{B} \boldsymbol{L}} \\
(\mathrm{mm})\end{array}$ & $\begin{array}{c}\boldsymbol{s}_{\text {calc }} \\
(\mathrm{mm})\end{array}$ & $\begin{array}{c}\sigma_{\max } / f_{t} \\
\%\end{array}$ & Failure mode \\
\hline BL150_DL_IT_1 & 3.67 & 530.96 & 0.59 & \multirow{2}{*}{0.21} & \multirow{2}{*}{0.37} & 47.15 & \multirow{5}{*}{ Textile slippage } \\
\hline BL150_DL_IT_2 & 3.04 & 439.81 & 0.57 & & & 39.06 & \\
\hline BL150_DL_UT_1 & 2.43 & 351.56 & 0.33 & \multirow{3}{*}{0.20} & \multirow{3}{*}{0.06} & 42.77 & \\
\hline BL150_DL_UT_2 & 2.27 & 328.41 & 0.23 & & & 39.95 & \\
\hline BL150_DL_UT_3 & 2.37 & 342.88 & 0.27 & & & 41.71 & \\
\hline BL200_SL_IT_1 & 4.61 & 667.00 & 6.71 & 1.22 & 5.49 & 59.24 & Textile slippage \\
\hline BL200_SL_IT_2 & 5.23 & 756.65 & 0.90 & 0.44 & 0.46 & 67.20 & Yarns' rupture \\
\hline BL150_SL_IT_1 & 3.69 & 533.85 & 0.94 & \multirow{2}{*}{0.50} & \multirow{2}{*}{0.65} & 47.41 & Yarns' rupture \\
\hline BL150_SL_IT_2 & 3.54 & 512.15 & 1.35 & & & 45.48 & Yarns' rupture \\
\hline BL100_SL_IT_1 & 3.25 & 470.20 & 0.52 & 0.30 & 0.22 & 41.76 & Textile slippage \\
\hline BL100_SL_IT_2 & 3.24 & 468.75 & 0.72 & 0.39 & 0.33 & 41.63 & Yarns' rupture \\
\hline BL200_SL_UT_1 & 2.32 & 335.65 & 0.45 & \multirow{2}{*}{0.25} & \multirow{2}{*}{0.19} & 40.83 & \multirow{6}{*}{ Textile slippage } \\
\hline BL200_SL_UT_2 & 2.20 & 318.29 & 0.44 & & & 38.72 & \\
\hline BL150_SL_UT_1 & 2.37 & 342.88 & 0.70 & \multirow{2}{*}{0.21} & \multirow{2}{*}{0.28} & 41.71 & \\
\hline BL150_SL_UT_2 & 2.17 & 313.95 & 0.29 & & & 38.19 & \\
\hline BL100_SL_UT_1 & 2.12 & 306.71 & 0.44 & \multirow{2}{*}{0.07} & \multirow{2}{*}{0.36} & 37.31 & \\
\hline BL100_SL_UT_2 & 1.99 & 287.91 & 0.43 & & & 35.03 & \\
\hline
\end{tabular}
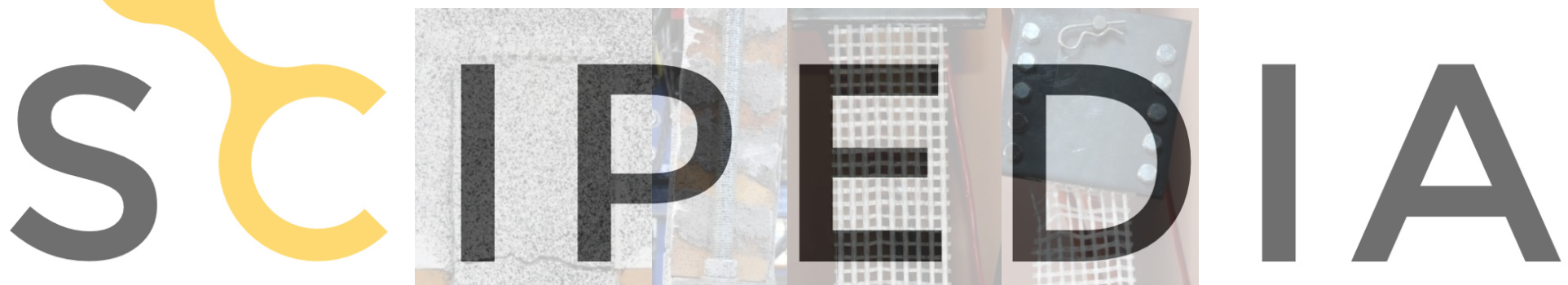

Register for free at https//www.scipedia.com to download the version without the watermark

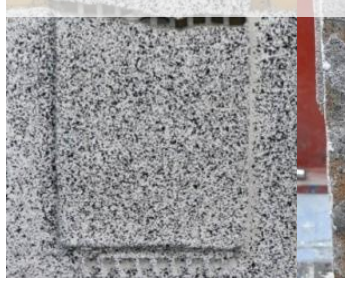

(a)

(b)

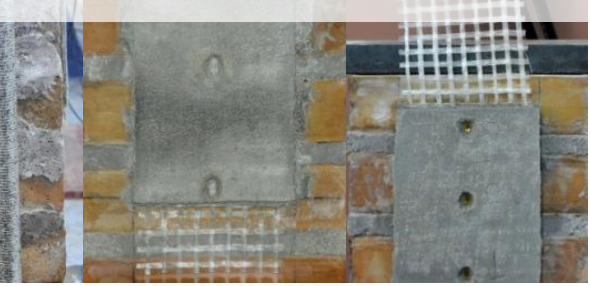

(c)

(d)

Figure 2: Images after failure depicting: (a) Textile slippage (side B) and (b) out-of-plane rotation of DL specimens, (c) textile slippage and (d) yarns' rupture in SL specimens

\subsection{Discussion}

The response of DL specimens with both UT and IT is depicted in Figure 3 through the respective curves of load versus relative displacement and load versus slip. Focusing on the former curves presented in Figure $3 \mathrm{a}$, it is revealed that up to the attainment of $F_{\max }$ both groups of specimens present a first linear and a second non-linear ascending branch. 
Additionally, $F_{\max }$ increased by $40 \%$ - on average - due to textile impregnation with the SBR latex emulsion. This is attributed to the consolidation of each yarn into a single macro-fiber leading to the absence of fibers' telescopic slippage and to the subsequent increase of the textile tensile strength (see subsection 2.2). In respect to the curves presented in Figure 3b, it is noted that slip values of specimens with UT have been derived from DDGFE records while those of specimens with IT have been computed through DIC analysis. Slip values of IT were almost zero up to points A1 and A2 which correspond to load values lower but close to the maximum one. After these points and up to $F_{\max }$ textile slippage increases rapidly due to the progressive debonding of the textile along its bond length. Starting from zero values at test start, slip values of UT kept on increasing up to $F_{\max }$; nevertheless, these values (the ones corresponding to $F_{\max }$ ) were much lower than the respective ones of the IT due to sleeve fibers' (filaments') rupture which is always present when glass fiber dry yarns are being pulled out from the matrix.

As previously mentioned (see subsection 4.1), DL specimens lost their symmetry in respect to the vertical plane normal to their faces after failure. In the case of UT, sleeve fibers' rupture led to an irrecoverable strength loss (descending branch of the load response curves - Figure 3a) due to the stress (and strain) lag of the core fibers in respect to the sleeve ones (telescopic pull-out effect). As a consequence, both the relative displacement of the fibrous reinforcement in respect to the substrate and the out-of-plane rotation of the specimens (at ultimate $\equiv$ zero load-bearing capacity) were much lower than the respective values derived from counterpart specimens furnished with IT. Indeed, in the case of IT and with the fibers remaining intact for the total duration of the test, the specimens' post-pedk response was characterized by a
temporary (and rather limited) load drop followed by a steady-rate load increase (Figure 3 a).
This phenomenon was attributed to the contribution of (extra) friction at the textile-to-matrix
interface on the convex side of the assemblage under testing during (and lue to) the indrease
of the out-of-plane rotation of the walls (which, in turn, was owed to the good bonding conditions and the integrity of the fiber yarns). In an attempt to further investigate the effect

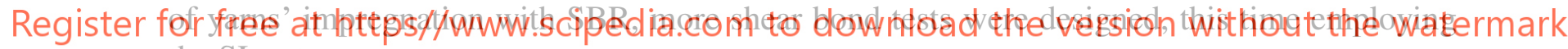
the SL set-up.

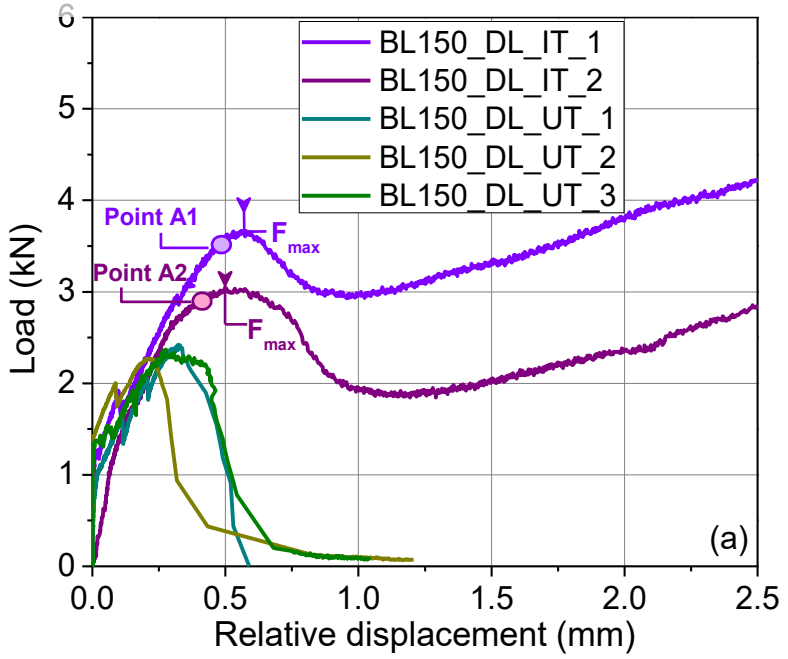

(a)

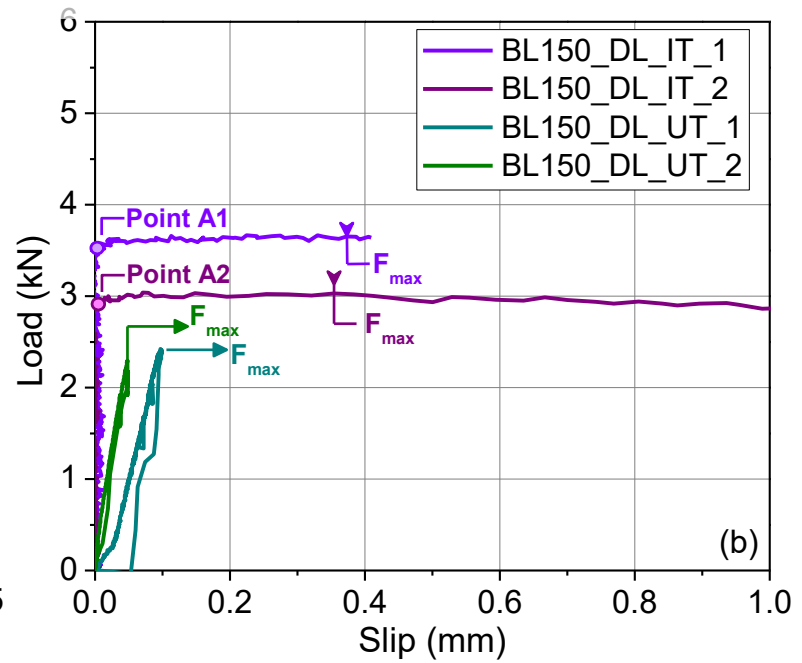

(b)

Figure 3: (a) Load vs. relative displacement and (b) load vs. slip curves of DL specimens 
The response of SL specimens with UT or IT is depicted in Figure 4 through load versus relative displacement curves. As mentioned before, all SL specimens with UT failed due to textile slippage from within the matrix. However, the dominant failure mode among SL specimens with IT was due to yarns' rupture close to the load introduction area reflected by an abrupt load drop in the respective response curves. Two SL specimens with IT (namely, BL200_SL_IT_1 and BL100_SL_IT_1) failed due to textile slippage (Figure 4a and 4c, respectively). From visual inspection and from the load versus relative displacement curve of specimen BL200_SL_1i it has become clear that the resulting response values have been contaminated by out-of-plane (Mode I) phenomena probably caused by misalignment between the unbonded part of the textile and the face of the specimen. Therefore, this specimen is excluded from the processing of the experimental results.

In Figure $4 \mathrm{~d}, F_{\max }$ values of all specimens tested are presented versus the bond length values considered. The increase of $F_{\max }$ due to textile impregnation was also confirmed in the case of SL specimens (though, only for BL = $100 \mathrm{~mm}$, taking into account the specimen with IT failing due to textile pull-out). This increase amounts to approximately 55\%. By comparing the $F_{\max }$ values of specimens with a bond length of $150 \mathrm{~mm}$ furnished with UT, it is inferred that the type of shear bond test set-up employed has negligible effect on $F_{\max }$. This is in accordance to the findings of [18]. Although not too obvious, it is noticed that the $F_{\max }$ values of specimens with UT (failing due to textile pull-out) show a load stabilization trend with increasing bond length which can be used (as a 'rule of thumb') for the determination of the effective bond length of the TRM/substrate joint under consideration. On the contrary, the $F_{\text {max }}$ values of speciniens with IT (failing due to stress concentration-inficted rupture of the
yarns) - or, equivalently the exploitation ratio of the textile's tensile strength - increase for
increasing bond length. The increase of the bond length reduces the level of load distribution
unevenness between different yarns in the textile layer (for a given value of total textile
resisting load) allowing it to undertake higher loads as the textile-to-matrix contact area increases. Failure finally occurs due to the inevitable load distribution unevenness between

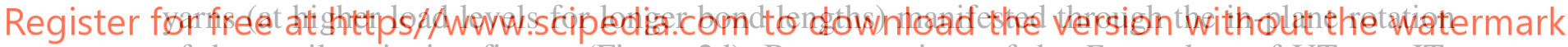
of the textile gripping fixture (Figure 2d). By comparison of the $F_{\max }$ values of UT- vs. ITfurnished SL specimens for each bond length considered a lower bound of the increase in the shear bond capacity of TRM/masonry joints due to textile impregnation with SBR latex can be determined. This amounts to $40 \%, 60 \%$ and $130 \%$ for a bond length of $100 \mathrm{~mm}, 150 \mathrm{~mm}$ and $200 \mathrm{~mm}$, respectively. Hence, the overall minimum increase in the shear bond capacity of $\mathrm{TRM} /$ masonry joints due to textile impregnation with SBR latex is equal to $40 \%$. 

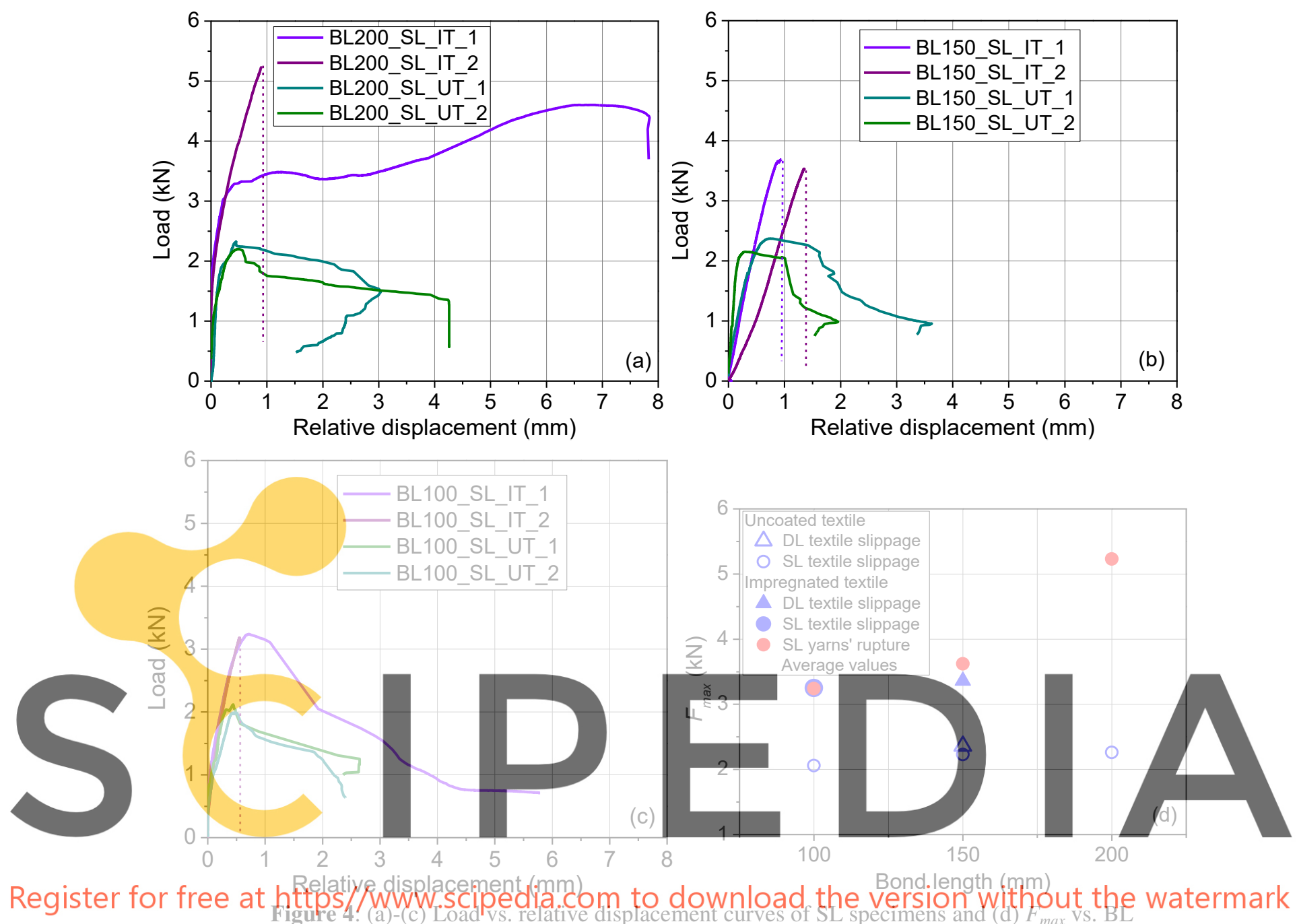

\section{CONCLUSIONS}

The currently presented experimental results concern the study of a TRM system consisted of AR-glass fiber textile embedded in cement-based mortar and applied on wall prisms made of smooth clay bricks. The effect of textile's full impregnation with SBR latex on the bond capacity of the TRM system was examined through the application of both DL and SL setups.

- The increase of load-bearing capacity of TRM/masonry joints under direct in plane shear loads due to textile impregnation with SBR latex was confirmed by employing both DL and SL set-ups. Depending on the set-up employed, this increase ranges between $40 \%$ and $55 \%$ for the type of TRM/masonry joints investigated in this work (failing due to textile pull-out from the matrix).

- For SL shear bond test configurations and for the same bond length considered, textile impregnation with SBR latex might result in the change of failure mode (from 
textile pull-out to textile rupture). Nevertheless, textile rupture occurs at an exploitation ratio of the textile's tensile strength much lower than $100 \%$ due to stress concentration phenomena at the vicinity of the textile gripping fixture. Hence, a lower bound of the increase in the shear bond capacity of TRM/masonry joints due to textile impregnation with SBR latex can be determined (40\%, 60\% and $130 \%$ for a bond length of $100 \mathrm{~mm}, 150 \mathrm{~mm}$ and $200 \mathrm{~mm}$, respectively). The exploitation ratio of the textile's tensile strength also increases with increasing bond lengths.

- It was verified that the type of set-up employed has negligible effect on the maximum transferable in-plane shear load along TRM/masonry interfaces.

- The behavior of IT-furnished DL specimens in terms of load vs. relative displacement response (pseudo-strain-hardening in the post-peak range) can be extrapolated to that of structural members receiving such TRM overlays as a means of flexural strengthening. Therefore, it would be logical to assume that the strengthening system will impart favorable energy dissipation capacity characteristics to the strengthened members.

Acknowledgements. The authors gratefully acknowledge Sika Hellas ABEE for providing the mortar.

\section{REFERENCES}

[1] Triantafillou, T. ed. Textile fibre composites in civil engineering. Woodhead Publishing (2016).

[2] D'Ambrisi, A., Feo, L. and Focacci, F. Experimental and analytical investigation on bond between Carbon-FRCM materials and masonry. Composites: Part B 46 (2013), pp. 15-20.

[3] Askouni, P.D. and Papanicolaou, C.G. Experimental investigation of bond between glass textile reinforced mortar overlays and masonry: the effect of bond length. Materials and Structures 50(2) (2017), pp. 164.

[4] Donnini, J., Corinaldesi, V. and Nanni, A. Mechanical properties of FRCM using carbon fabrics with different coating treatments. Composites: Part B, 88 (2016), pp. 220-228.

[5] Donnini, J. and Corinaldesi, V. Mechanical characterization of different FRCM systems for structural reinforcement. Construction and Building Materials 145 (2017), pp. 565575.

[6] Leone, M., Aiello, M.A., Balsamo, A., Carozzi, F.G., Ceroni, F., Corradi, M., Gams, M., Garbin, E., Gattesco, N., Krajewski, P., Mazzotti, C., Oliveira, D., Papanicolaou, C.G., Ranocchiai, C., Roscini, F. and Saenger, D. Glass fabric reinforced cementitious matrix: Tensile properties and bond performance on masonry substrate. Composites Part B 127 (2017), pp. 196-214.

[7] D'Antino, T. and Papanicolaou, C. Comparison between different tensile test set-ups for the mechanical characterization of inorganic-based composites. Construction and Building Materials 171 (2018), pp. 140-151.

[8] De Andrade Silva, F., Butler, M., Hempel, S., Toledo Filho, R.D. and Mechtcherine, V. Effects of elevated temperatures on the interface properties of carbon textile-reinforced concrete. Cement and Concrete Composites, 48 (2014), pp.26-34. 
[9] Aljewifi, H., Fiorio, B. and Gallias, J.L. Characterization of the impregnation by a cementitious matrix of five glass multi-filament yarns. European journal of environmental and civil engineering 14(5) (2010), pp.529-544.

[10] Schneider, K., Michel, A., Liebscher, M., Terreri, L., Hempel, S. and Mechtcherine, V. Mineral-impregnated carbon fibre reinforcement for high temperature resistance of thin-walled concrete structures. Cement and Concrete Composites 97 (2019), pp.68-77.

[11] Lorenz, E., Schütze, E. and Weiland, S. Textile Reinforced Concrete-Properties of the Composite Material. BETON-UND STAHLBETONBAU 110 (2015), pp.29-41.

[12] Rempel, S., Kulas, C. and Hegger, J. Bearing behavior of impregnated textile reinforcement. In: Brameshuber, W. (Ed.), 11th International Symposium on Ferrocement (FERRO-11) and 3rd International Conference on Textile Reinforced Concrete (ICTRC3), Aachen, Germany, 7-10 June 2015, pp. 71-77.

[13] RILEM TC 76. (1991). "Technical recommendations for testing and use of constructions materials: LUMB1." Chapman \& Hall, UK.

[14] (CEN) European Committee for Standardization. (2005). "Design of masonry structures, part 1.1." Eurocode 6, Brussels.

[15] British Standard. (1999). "Textiles-Tensile properties of fabrics, part 1." EN ISO 13934, UK.

[16] (CEN) European Committee for Standardization. (1993). "Methods of test for mortar for masonry, part 11." EN 1015, Brussels.

[17] Sneed, L.H., D'Antino, T., Carloni, C. and Pellegrino, C. A comparison of the bond behavior of PBO-FRCM composites determined by double-lap and single-lap shear tests. Cement and Concrete Composites 64 (2015), pp. 37-48.

[18] Askouni, P.D. and Papanicolaou, C.G. Comparison of double-lap/double-prism and single-lap/single-prism shear tests for the TRM-to-masonry bond assessment, In: Mechtcherine V., Slowik V., Kabele P. (eds) Strain-Hardening Cement-Based Composites, SHCC 2017, RILEM Bookseries 15, Springer, Dordrecht, (2018) 527-534. 